\title{
Morfometria em abordagem multivariada como ferramentas para auxiliar na compreensão e delimitações taxonômicas de Peltogyne: estudo de caso com $P$. pauciflora e suposto sinônimo $P$. glaziovii
}

\author{
Fernanda Gomes Silva ${ }^{1}$; Isys M. Souza ${ }^{2}$; Ligia S. Funch ${ }^{3}$ \\ 1. Bolsista PROBIC/CNPq, Graduando em Licenciatura em Ciências Biológicas, Universidade Estadual de Feira de \\ Santana, e-mail: fernandagomes0104@gmail.com \\ 2. Participante do projeto ou núcleo tal, DCBIO, Universidade Estadual de Feira de Santana, e-mail: \\ isys.souza@gmail.com \\ 3. Orientador, DCBIO, Universidade Estadual de Feira de Santana, e-mail: $\underline{\text { ligiafunch } @ \text { yahoo.com }}$
}

PALAVRAS-CHAVE: Morfometria, taxonomia, Abordagem multivariada.

\section{INTRODUÇÃO}

Peltogyne é um gênero de Leguminosae (Detarioideae, LPWG 2017) com distribuição neotropical, ocorrendo desde o México até o sudeste do Brasil, que reúne um total de 24 espécies, sendo a Amazônia Central seu principal centro de distribuição geográfica (Silva 1976; Flora do Brasil 2020). Foram encontrados problemas em relação à delimitação taxonômica de algumas espécies, a exemplo da sinonimização de $P$. glaziovii em P. pauciflora proposta na revisão do gênero por Silva (1976). Sabendo disso, a pesquisa busca com a utilização da Morfometria em abordagem multivariada, responder e compreender as delimitações taxonômicas de Peltogyne: no estudo de caso com P. pauciflora e suposto sinônimo P. glaziovii, tomando como base a análise dos espécimes, e uma matriz morfométrica desses espécimes encontrados no estado da Bahia.

\section{MATERIAL E MÉTODOS}

A análise e coleta de dados foram realizadas a partir da confecção de uma matriz morfológica, utilizando: as medidas foliares propostas por Souza et al. (2014), não foram utilizados os caracteres reprodutivos devido a falta de exsicatas com um número expressivo de flores e frutos. Foram realizadas consultas dos espécimes através do banco de dados do CRIA - Centro de Referência e Informação Ambiental, bem como consultas presenciais no (HUEFS) sendo feito o uso do software específico (PAST, Hammer et al. 2001) para depositar os dados morfológicos obtidos. Foram realizadas também: análises de agrupamento utilizaram à média de grupo (UPGMA), Análises dos Principais Componentes (PCA) Análises de Dissimilaridade (ANOSIM; Warwick, Clarke and Suharsono 1990) e Análises de Variância Multivariada Não-Paramétrica 
(NPMANOVA; Anderson 2001). Os mapas de distribuição dos espécimes foram preparados utilizando o software (ArcGIZ) e a partir das coordenadas geográficas presentes nas etiquetas de herbário.

\section{RESULTADOS E/OU DISCUSSÃO}

As Análises de Componentes Principais (PCA), realizadas com base na matriz morfométrica, verificou a quantidade de variância existente entre P.pauciflora e P.glaziovii, utilizando medidas precisas do tamanho e forma dos atributos foliares, para averiguar o quanto essas espécies diferem entre si, possuindo como finalidade, constatar se essa metodologia responde então a separação dessas espécies, que são tidas como sinônimas de acordo com o Flora do Brasil 2020. A partir da análise feita com (PCA) as características presentes nessas espécies diferem, há uma separação das espécies quando os dados referentes a elas, quando esses dados são inseridos, essa representação pode ser vista na (figura 2) demostrado pelo diagrama. A análise de agrupamento verificando o quanto essas espécies variam entre si, e como são bem delimitadas a partir de uma representação de um Dendograma (figura 3). Os resultados da UPGMA e PCA foram consistentes com ANOSIM e NPMANOVA. Comparações das variedades de Peltogyne mostraram diferenças significativas $(\mathrm{p}<0,0002)$ entre as variedades P.pauciflora e P.glaziovii, como representado na (figura 4). O mapa de distribuição, (figura 5) demostra que essas espécies correspondem a linhagens bem delimitadas geograficamente.

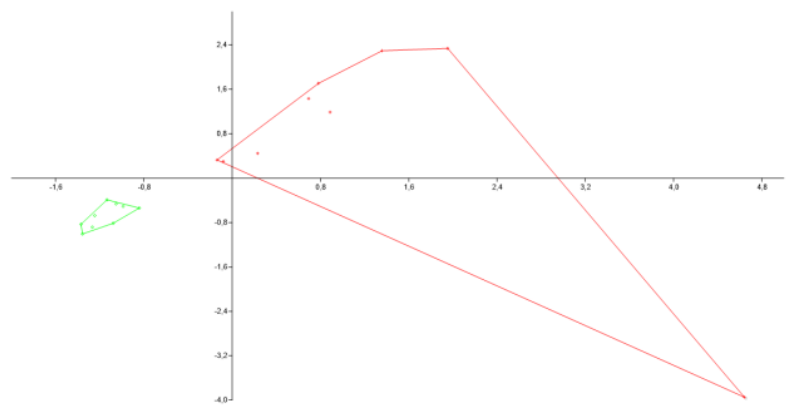

Figura 2. Diagrama: Em verde $P$. pauciflora, vermelho- P.glaziovii.

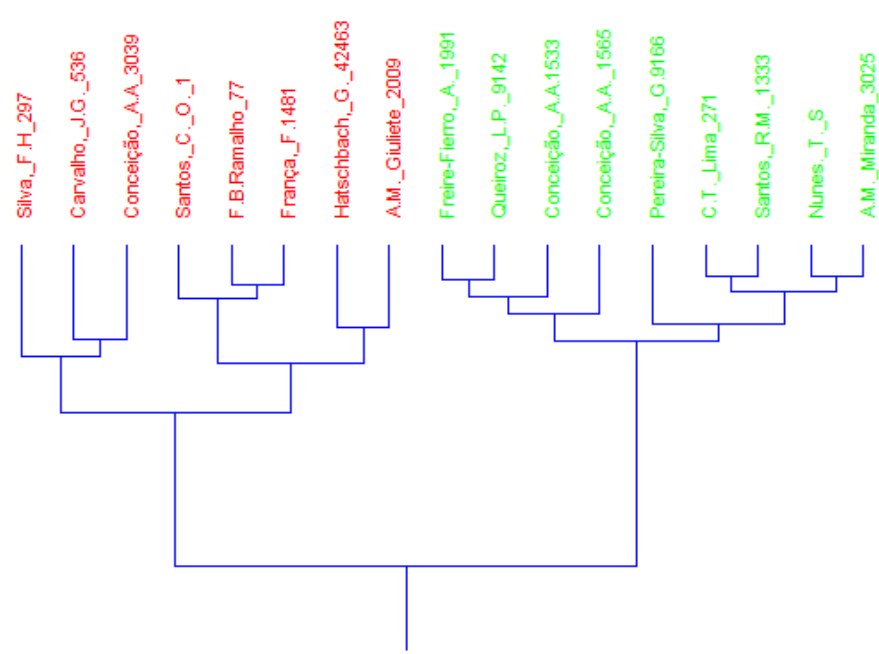

Figura 3. Dendograma : em verde $P$. pauciflora, vermelho- P.glaziovii.

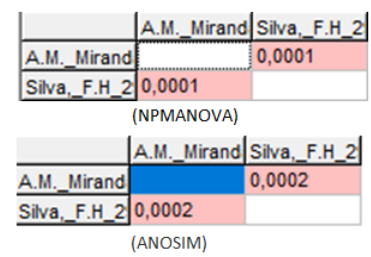

Figura 4. (NPMANOVA e ANOSIM). 


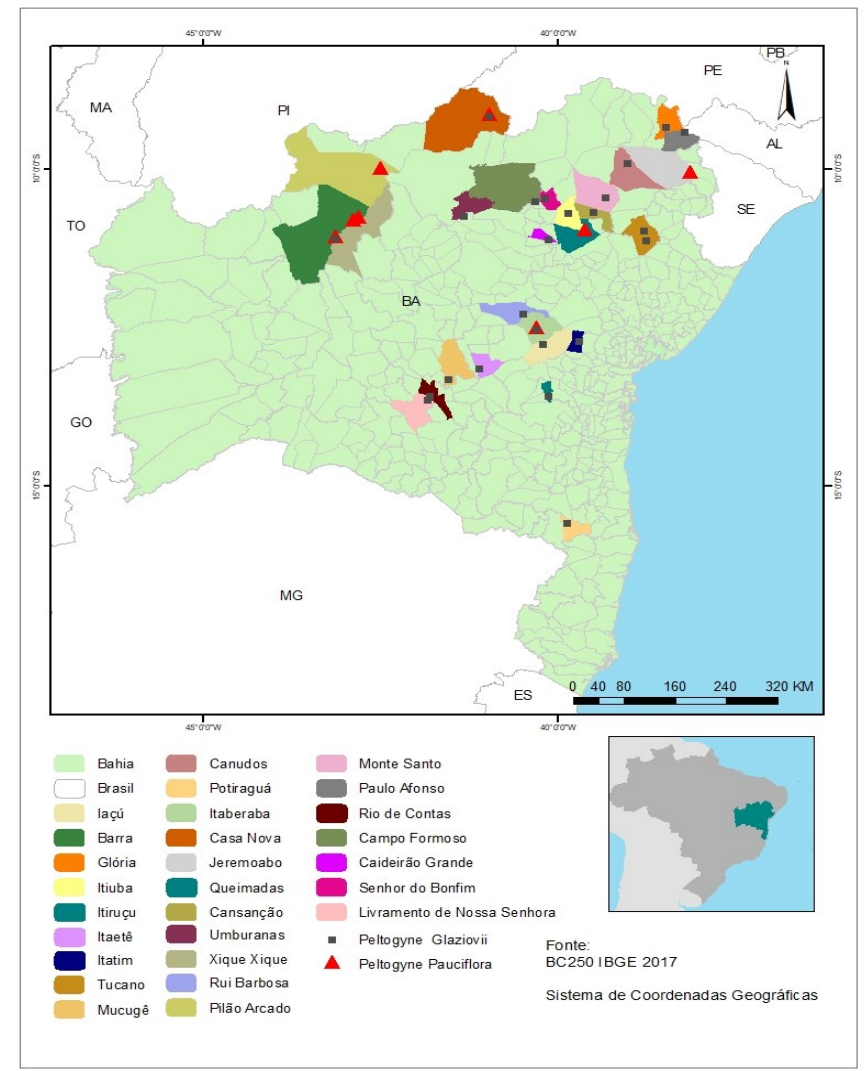

Figura 5. Mapa de distribuição do estado da Bahia de $P$. pauciflora, representado pelo símbolo quadrado e P.glaziovii pelo símbolo triangulo. Correspondendo a linhagens bem delimitadas geograficamente.

\section{Descrição:}

Peltogyne pauciflora Benth., Fl. Bras. 15(2): 234. 1870

Árvores ou arbustos 1,0-5,0 m alt.; ramos glabros. Pecíolo 0,2-0,4cm compr., glabro; peciólulo 0,1 cm compr., glabro. Folíolos 2,0-3,2 × 1,2-1,9 cm, não-falcados a levemente falcados, elípticos, ápice agudo e retuso, base oblíqua, lado interno agudo, lado externo truncado, margem inteira, papiráceos, face adaxial e abaxial glabras a glabrescentes. Panícula 1,3- 6,3 cm compr., congesta, mais curta a mais longa que a folha adjacente; pedicelo 0-0,2 cm compr.; botão floral 0,2-0,6 $\times 0,2-0,3 \mathrm{~cm}$, curto a longo-capitado. Flor 0,5 - 1,0 cm compr.; hipanto ca. 0,1 cm compr., base subséssil a alongada $(0,1-0,2 \mathrm{~cm}$ compr.); sépalas $0,3-0,4 \times 0,3 \mathrm{~cm}$, elípticas; pétalas $0,3-0,4 \mathrm{~cm}$, elípticas; filetes ca. 0,3 cm compr., anteras $0,1 \mathrm{~cm}$ compr.; ovário $0,2 \times 0,1 \mathrm{~cm}$, hemiorbicular, glabro a pubescente, estípite ca. 0,05 cm compr., estilete ca. 0,3 cm compr. Fruto 3,0-3,8 $\times$ 2,2-3,0 cm, deiscente, lenhoso, oblongo a orbicular, não-alado. Semente não vista. 
Peltogyne glaziovii Silva.1976, F.G.Silva, I.M. Souza \& Funch. 2018.

Árvores ou arbustos 1,0-8,0 m alt.; ramos glabros. Pecíolo 0,4-1,5 cm compr., glabro; peciólulo 0,1-0,2 cm compr., glabro. Folíolos 2,3-7,3 × 1,2-3,8 cm, não-falcados, elípticos, ápice agudo, obtuso, retuso, base oblíqua, lado interno agudo, lado externo levemente arredondado, margem inteira, papiráceos, face adaxial e abaxial glabras a glabrescentes. Panícula 2,0-5,5 cm compr., congesta, mais curta a mais longa que a folha adjacente; pedicelo $0,2-0,4 \mathrm{~cm}$ compr.; botão floral $0,2-0,3 \times 0,2-0,3 \mathrm{~cm} \mathrm{~cm}$ curto a longo-capitado. Flor 0,5-0,7 cm compr.; hipanto ca. 0,1 cm compr., base subséssil a alongada (0,1-0,2 $\mathrm{cm}$ compr.); sépalas $0,3-0,4 \times 0,2 \mathrm{kcm}$, elípticas; pétalas $0,2-0,3 \mathrm{~cm}$, elípticas; filetes ca. 0,3 cm compr., anteras $0,1 \mathrm{~cm}$ compr.; ovário $0,2 \times 0,1$ $\mathrm{cm}$, hemi-orbicular, glabro a pubescente, estípite ca. $0,05 \mathrm{~cm}$ compr., estilete ca. $0,3 \mathrm{~cm}$ compr. Fruto 1,4 -3,0 × 1,1-2,7cm, deiscente, não lenhoso, oblongo a hemi-orbicular, não alado. Semente não vista. Para um melhor entendimento, fizemos uma representação dos folíolos de cada espécie, demonstrando sua morfologia distinta.

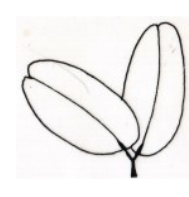

A.(P.pauciflora)

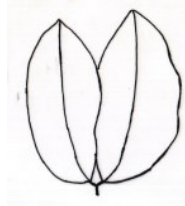

B. (P.glaziovii)

\section{CONSIDERAÇÕES FINAIS}

O presente estudo confirma que morfometria foliar suporta a separação de P. glaziovii e P. pauciflora, enquanto espécies distintas, não confirmando a sinonimização proposta na revisão do gênero para essas espécies.

\section{REFERÊNCIAS}

ALMEIDA, M.E. DE, GOTTLIEB, O.R., SOUZA, J.K. DE; TEIXEIRA, M.A. 1974. SILVA, M.F. 1976. Revisão taxonômica do gênero Peltogyne Vog. (Leguminosae Caesalpinioideae). Acta Amazônica 1: 1-61.

$<$ http://floradobrasil.jbrj.gov.br/jabot/floradobrasil/FB83557>. Acesso em 24 jul. 2017. NAIR, C.A. 2006; Técnicas multivariadas na determinação da diversidade genética em gergelim usando marcadores RAPD.

SOUZA, M.2014. Análises morfológicas sugerem uma nova circunscrição taxonômica para Hymenaea courbarilL. (Leguminosae, Caesalpinioideae) 